\title{
Apathy in Parkinson's disease is related to executive function, gender and age but not to depression
}

\author{
Antonia Meyer ${ }^{1}$, Ronan Zimmermann ${ }^{1}$, Ute Gschwandtner ${ }^{1}$, Florian Hatz ${ }^{1}$, Habib Bousleiman ${ }^{1,2}$, \\ Nadine Schwarz ${ }^{1}$ and Peter Fuhr ${ }^{1 *}$ \\ Clinical Neurophysiology,Department of Neurology, Hospital of the University of Basel, Basel, Switzerland \\ ${ }^{2}$ Epidemiology and Public Health, Swiss Tropical and Public Health Institute, University of Basel, Basel, Switzerland
}

\section{Edited by:}

Tania Álvarez Avellón, Universidad

de Oviedo, Spain

Reviewed by:

Valentina Echeverria Moran, Bay

Pines VA Medical Center, USA

Alessandro Martorana, University of

Rome Tor Vergata, Italy

Tania Álvarez Avellón, Universidad

de Oviedo, Spain

*Correspondence:

Peter Fuhr, Department of

Neurology, Hospital of the

University of Basel, Petersgraben 4,

4031 Basel, Switzerland

e-mail:peter.fuhr@usb.ch
Deficits in executive functions occur in up to $93 \%$ of patients with Parkinson's disease (PD). Apathy, a reduction of motivation and goal-directed behavior is an important part of the syndrome; affecting both the patients as well as their social environment. Executive functions can be subdivided into three different processes: initiation, shifting and inhibition. We examined the hypotheses, (1) that apathy in patients with Parkinson's disease is only related to initiation and not to shifting and inhibition, and (2) that depression and severity of motor signs correlate with apathy. Fifty-one non-demented patients ( $19=$ female) with PD were evaluated for apathy, depression and executive functions. Executive function variables were summarized with an index variable according to the defined executive processes. Linear regression with stepwise elimination procedure was used to select significant predictors. The significant model $\left(R^{2}=0.41 ; p<0.01\right)$ revealed influences of initiation $(b=-0.79 ; p<0.01)$, gender $(b=-7.75 ; p<0.01)$, age $(b=-0.07 ; p<0.05)$ and an age by gender interaction $(b=0.12 ; p<0.01)$ on apathy in Parkinson's disease. Motor signs, depression and level of education did not influence the relation. These results support an association of apathy and deficits of executive function in PD. Initiation strongly correlates with apathy, whereas depression does not. We conclude, that initiation dysfunction in a patient with Parkinson's disease heralds apathy. Apathy and depression can be dissociated. Additionally, apathy is influenced by age and gender: older age correlates with apathy in men, whereas in women it seems to protect against it.

Keywords: apathy, Parkinson's disease, executive functions, depression, gender, age

\section{INTRODUCTION}

Apathy is defined as a primary loss of motivation, a loss of interest and reduced goal-directed behavior (Levy and Dubois, 2006; Starkstein et al., 2012). Apathy is a predictive factor for cognitive deterioration in Parkinson's disease (PD) (Dujardin et al., 2009); and has significant impact on quality of life (Zesiewicz et al., 2010; Chaudhuri et al., 2011).

Executive dysfunctions are highly prevalent in PD, affecting up to $93 \%$ of the patients, depending on the disease stage (Emre, 2003) and correlate with apathy (Pluck and Brown, 2002; Zgaljardic et al., 2007; Dujardin et al., 2009).

Executive functions comprise several processes which may be independently impaired (Miyake et al., 2000; Drechsler, 2007; Stuss and Alexander, 2007). Drechsler (2007) identified three executive processes: initiation, inhibition and shifting. Initiation is defined as the ability to start intentional actions self-motivated. Impairments in this process are associated with tests, in which patients are self-generating a processing speed or starting an action. Inhibition is characterized by the ability to suppress a reaction. Patients with impaired inhibition are showing impulsive response behavior and a high level of distractibility. Shifting means the ability to relocate the focus of attention from one to another target. It is reduced if a subject shows cognitive inflexibility and tests measuring this executive process are characterized by changing criteria within the task (Drechsler, 2007).

Major depression is present in up to a third of all patients with PD (Reijnders et al., 2010) and overlaps with apathy (Pluck and Brown, 2002; Kirsch-Darrow et al., 2006; Starkstein et al., 2009). However, there is evidence, that the two syndromes can be dissociated (Levy et al., 1998; Kirsch-Darrow et al., 2006).

Apathy due to frontal lesions shows a decreased performance in tests measuring the initiation process (Drechsler, 2007). We assume that dysfunction of initiation also predicts apathy in PD. Furthermore, we expected apathy to be related to depression. Several examinations have shown a relation between apathy and motor signs (Pedersen et al., 2010; Cubo et al., 2012), and therefore, we expected motor signs to be predictive for apathy. The aim of this study is to investigate the association of neuropsychological, psychiatric and motor factors with apathy in PD.

\section{MATERIALS AND METHODS PATIENTS}

Fifty-eight patients with PD were recruited between October 2011 and April 2013 from the movement disorders clinic of the Basel University Hospital or through advertisements. The patients were participants of a Cognitive training-study (Zimmermann 
et al., 2014) and underwent neuropsychological, psychiatric and neurological assessment. Inclusion criteria for the study were idiopathic PD according to UK Parkinson's disease Brain Bank Criteria (Gibb and Lees, 1988) and written informed consent. Patients were excluded if they had moderate or severe dementia (Mini Mental State Examination (MMSE) $\leq 24$; Folstein et al., 1975), insufficient knowledge of the German language, other severe brain disorders, alcohol or drug dependency. For this study, the data of $n=51$ patients (19 female, 32 male) has been analyzed. Seven patients were excluded because of having deep brain stimulation $(n=3)$, an unfulfilled apathy questionnaire $(n=3)$ or because German was not their native language $(n=1)$ (see Supplementary Figure 1). All patients were on dopaminergic medication and were tested in the $\mathrm{ON}$ state.

\section{PSYCHIATRIC AND PSYCHOLOGICAL ASSESSMENT Apathy}

Apathy was measured with the German version of the Apathy Evaluation Scale $\left(\mathrm{AES}_{\mathrm{D}}\right.$; Lueken et al., 2006) filled out by a relative or a person close to the patients. This questionnaire consists of 18 items, which are evaluated on a four-point Likert scale, ranging from not at all (i.e., 0 points) to a lot (i.e., 3 points). For each patient, a total value was calculated with a maximum of 54 and minimal of zero point with higher values indicating more severe apathy.

\section{Depression}

Symptoms of depression were measured with a self-rating scale, the German version of Beck Depression Inventory II $\left(\mathrm{BDI}_{\mathrm{D}}\right.$; Hautzinger et al., 1995). The 21 items are answered on a fourpoint Likert scale, ranging from zero (e.g., I do not feel sad) to three (e.g., I am so sad and unhappy that I can't stand it). Based on the evaluation of each item, a total score was calculated. Maximum score is 63 and minimal score is zero, whereby higher values are indicating more severe depression.

\section{NEUROLOGICAL ASSESSMENT}

The severity of motor signs was assessed using Unified Parkinson's disease Rating Scale (UPDRS; Fahn and Elton, 1987), subscale III, applied by trained neurologists. This scale consists of 13 items which are evaluated on a four-point Likert scale. The patients are interrogated and examined about their motor issues (e.g., speech, mimicry, rest tremor, bradykinesia etc.). A total score is calculated with zero being minimal and 54 being the maximum value.

\section{NEUROPSYCHOLOGICAL TESTS OF EXECUTIVE FUNCTIONS AND CLASSIFICATION OF VARIABLES}

The classification of the variables follows Drechsler's (2007) definition of executive functions (see Table 1 ). The executive variables were classified each to one executive process by the consensus of two raters, and were then converted into z-scores and summarized to an index variable; initiation, shifting and inhibition. Additional information about the tests and analyzed variables is annexed in the Supplementary Material (see Supplementary, description of tests and measures).

\section{Initiation}

The initiation process was measured with:

- Semantic Fluency (Morris et al., 1989)

- Phonemic Fluency (Thurstone and Thurstone, 1948)

- 5 Point Test (Regard et al., 1982)

- Trail Making Test (Reitan, 1958)

- Stroop Test (Stroop, 1935)

\section{Shifting}

The shifting process was measured with:

- Modified Wisconsin Card Sorting Test (Nelson, 1976)

- California Verbal Learning Test (Delis et al., 1987)

- Trail Making Test (Reitan, 1958)

- Flexibility [Test of Attentional Performance (TAP); Zimmermann and Fimm, 2007]

\section{Inhibition}

The inhibition process was measured with:

- Stroop Test (Stroop, 1935)

- Trail Making Test (Reitan, 1958)

- Divided Attention (TAP: Zimmermann and Fimm, 2007)

- Working Memory (TAP: Zimmermann and Fimm, 2007)

\section{STATISTICAL ANALYSIS}

Level of statistical significance was set to $p<0.05$. R version 3.0.1 was used for the analysis (R Core Team, 2012). All variables were

Table 1 | Performance in tests measuring executive functions.

\begin{tabular}{lllc}
\hline $\begin{array}{l}\text { Executive } \\
\text { process }^{\mathbf{a}}\end{array}$ & Test & Variable & Mdn [quantile] \\
\hline Initiation & Phonemic fluency & Correct answers & $12[10,15]$ \\
& Semantic fluency & Correct answers & $21[17.5,23]$ \\
& 5 point test & Correct figures & $23[18.5,28.5]$ \\
& TMT & TMT A & $45[37,58.5]^{\mathrm{b}}$ \\
& Stroop & Naming colors & $14[13.7,17]^{\mathrm{b}}$ \\
\hline Shifting & mWCST & Perseverative errors & $1[0,2.5]$ \\
& CVLT & Perseverative errors & $2[0.5,3]$ \\
& TMT & TMT B/A (ratio) & $2.9[1.9,2.7]$ \\
& Flexibility & Reaction time & $4[1,9]^{\mathrm{C}}$ \\
\hline Inhibition & Stroop & Interference & $1.8[1.6,2.1]$ \\
& TMT & TMT B, errors & $0[0,1]$ \\
& Divided attention & Errors & $3[1,6]$ \\
& Working memory & Errors & $5[2,7.5]$ \\
\hline
\end{tabular}

${ }^{a}$ Classification according to Drechsler (2007). All medians (quantiles) represent raw values. Quantile refer to 25th and to the 75th percentile. TMT, Trail Making Test; mWCST, modified Wisconsin Card Sorting Test; CVLT, California Verbal Learning Test.

${ }^{b}$ Seconds.

${ }^{c}$ Milliseconds. 
averaged over the patients and $\mathrm{z}$-scored; variables indicating good performance in smaller values were inversed.

The apathy total score was not normally distributed (Kolmogorov Smirnow Test $(\mathrm{KST}): p<0.01)$ therefore, this variable was square root transformed, leading to a non-significant $p$-value ( $p=0.34$ ) of the KST. After $\mathrm{z}$-score transformation, the executive function variables were averaged per each executive process: initiation, shifting and inhibition. To check the validity of the sub processes of executive functions, the intercorrelations between all the collected $\mathrm{z}$-transformed cognitive variables and internal consistency (Cronbach's alpha) were calculated. As defined by George and Mallery (2003), acceptable internal consistency was set at Cronbach's $\alpha$ of greater or equal to 0.70 . A linear regression model with Akaike Information Criterion (AIC) based stepwise backwards elimination procedure (Venables and Ripley, 2002) was applied to select the relevant predictors of apathy. The analyses were performed using initiation, inhibition, switching, age, gender, education and subscale III of the UPDRS as potential predictors for $\mathrm{AES}_{\mathrm{D}}$ total score. Multiple $R^{2}$ (coefficient of determination) and F-statistics were used for characterization of the overall model. The $\mathrm{R}$ package relaimpo (Grömping, 2006) was used to evaluate the relative importance of the regressors. Relaimpo splits the explained variance $\left(R^{2}\right)$ according to the importance of the predictors (Grömping, 2006).

\section{RESULTS}

\section{PATIENTS}

Low average total scores of apathy and depression were found in our sample of $51 \mathrm{PD}$ patients. According to the proposed cut-off score of 19 points in the $\mathrm{AES}_{\mathrm{D}}$ (Leentjens et al., 2008), $8 \%$ of the patients met the criteria for clinical relevant apathy. In $8 \%$ of the included patients, a total score in the $\mathrm{BDI}_{\mathrm{D}}$ of $\geq 14$ was observed. Therefore, most of the patients had sub-syndromal depression as defined by Schrag et al. (2007). Table 2 shows the properties of the sample.

INTERNAL CONSISTENCY OF INITIATION, INHIBITION, AND SHIFTING The internal consistency for initiation was Cronbach's $\alpha=0.78$. This finding indicates acceptable internal consistency for this

Table 2 | Sample description.

\begin{tabular}{|c|c|}
\hline & Mdn [quantile] $]^{\mathrm{a}}$ \\
\hline \multicolumn{2}{|c|}{ Patients ( $n=51,19$ Female) } \\
\hline Age (years) & $67[32,73]$ \\
\hline Education (years) & $15[13,16]$ \\
\hline$A E S_{D}$ & $6[2,13]$ \\
\hline$B D I_{D}$ & $8[4,11.5]$ \\
\hline MMSE & $29[28,30]$ \\
\hline UPDRS, subscale III & $14.5[7.6,21]$ \\
\hline Hoehn and Yahr stage & $2[0,2]$ \\
\hline LED (mg/day) & $600[300,947]$ \\
\hline Disease duration (years) & $4[2,6.5]$ \\
\hline
\end{tabular}

a All values represent median [quantiles]. Quantiles refer to 25th and to the 75th percentile. $A E S_{D}$, Apathy Evaluation Scale; $B D I_{D}$, Beck Depression Inventory; UPDRS, Unified Parkinson's Disease Rating Scale; LED, L-Dopa- Equivalent Dose. executive process. In contrast, it was inadequate for inhibition (Cronbach's $\alpha=0.48$ ) and shifting (Cronbach's $\alpha=0.41$ ).

The significant model $\left(R^{2}=0.41 ; p<0.01\right)$ revealed influences of initiation $(b=-0.79 ; p<0.01)$, gender $(b=-7.75$; $p<0.01)$, age $(b=-0.07 ; p<0.05)$ and an age by gender interaction $(b=0.12 ; p<0.01)$ on apathy in PD. Motor signs, depression and level of education did not influence the relation.

\section{PREDICTORS FOR APATHY}

By stepwise elimination the following variables were excluded from the model: depression, inhibition, shifting and education. The parameters initiation $(b=-0.79 ; p<0.01)$, age $(b=-0.07$; $p>0.05)$, gender $(b=-7.75 ; p<0.01)$ and the interaction of age by gender $(b=0.12 ; p<0.01)$ remained in the model explaining apathy. Furthermore, the UPDRS subscale III was not significant in the prediction of the $\mathrm{AES}_{\mathrm{D}}$ total score $(b=-0.01$; $p=0.18$ ), but remained in the model according to AIC. The overall model was significant $\left(p<0.01 ; R^{2}=0.41\right)$; adjusted $R^{2}=0.35 ; F_{(5,44=6.24)}$. According to Cohen (1992) an adjusted $R^{2}$ of 0.35 can be interpreted as a strong effect. The calculation of the relative importance of the regressors in the model showed, that initiation and the interaction age by gender were the most important variables predicting apathy in PD. Initiation explained $17 \%$, the age by gender interaction $15 \%$, gender $6 \%$ and age $2 \%$ of the variance of apathy. The age by gender interaction showed that, in men, the $\mathrm{AES}_{\mathrm{D}}$ total score was positively correlated with age $(b=0.06 ; p<0.05)$ while it was negatively correlated in women $(b=-0.06 ; p<0.05)$ (see Figure 1).

\section{INTERCORRELATIONS}

Table 3 shows the intercorrelations of apathy and the executive functions variables. With exception of phonemic fluency, all variables categorized as initiation (Semantic Fluency, Five Point Test, Trail Making Test, Stroop Test) correlated significantly and negatively with apathy (see Figure 2).

\section{DISCUSSION}

Apathy is related to executive dysfunction in patients with PD but not to depression or motor signs. As hypothesized, the executive process of initiation is the most influential factor in this association. Incongruent with our initial hypothesis, neither depression nor

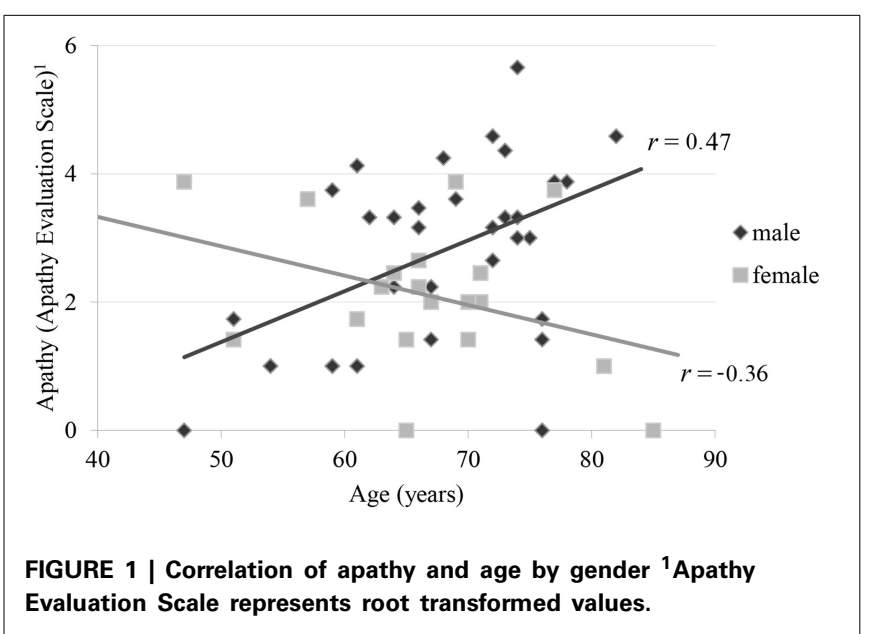


Table 3 | AES , Apathy Evaluation Scale; 5PT, Five Point Test; TMT, Trail Making Test; mWCST, modified Wisconsin Card Sorting Test; CVLT, California Verbal Learning Test; RT, reaction time.

\begin{tabular}{|c|c|c|c|c|c|c|c|c|c|c|c|c|c|c|}
\hline & 1 & 2 & 3 & 4 & 5 & 6 & 7 & 8 & 9 & 10 & 11 & 12 & 13 & 14 \\
\hline 1. $A E S_{D}$, total score & 1 & & & & & & & & & & & & & \\
\hline Initiation & $-0.44^{* *}$ & & & & & & & & & & & & & \\
\hline 3. Animals, correct words & $-0.35^{* *}$ & $-0.45^{* *}$ & 1 & & & & & & & & & & & \\
\hline 4. 5PT, correct figures & $-0.36^{* *}$ & $0.32 *$ & $0.56 * *$ & 1 & & & & & & & & & & \\
\hline Shifting & -0.26 & & & & & & & & & & & & & \\
\hline 7. mWCST, perseverative errors & $s-0.25$ & -0.11 & 0.25 & $0.29 *$ & 0.26 & 0.09 & 1 & & & & & & & \\
\hline 8. CVLT, perseverative errors & 0.03 & 0.20 & 0.00 & -0.02 & -0.21 & 0.13 & -0.22 & 1 & & & & & & \\
\hline 9. TMT, B/A (ratio) & -0.08 & $0.35^{*}$ & $0.37^{* *}$ & $0.42 * *$ & 0.04 & 0.24 & 0.25 & 0.00 & 1 & & & & & \\
\hline 10. Flexibility RT & -0.24 & $-0.30^{*}$ & $0.37 * *$ & $0.35^{*}$ & $0.31^{*}$ & $0.38^{* *}$ & 0.12 & -0.14 & 0.26 & 1 & & & & \\
\hline 14. Working memory, errors & -0.09 & 0.02 & 0.24 & 0.22 & 0.12 & -0.07 & $0.31^{*}$ & -0.08 & $0.38^{* *}$ & 0.15 & 0.06 & $0.34^{*}$ & 0.23 & 1 \\
\hline
\end{tabular}

${ }^{* *} p<0.01,{ }^{*} p<0.050$.

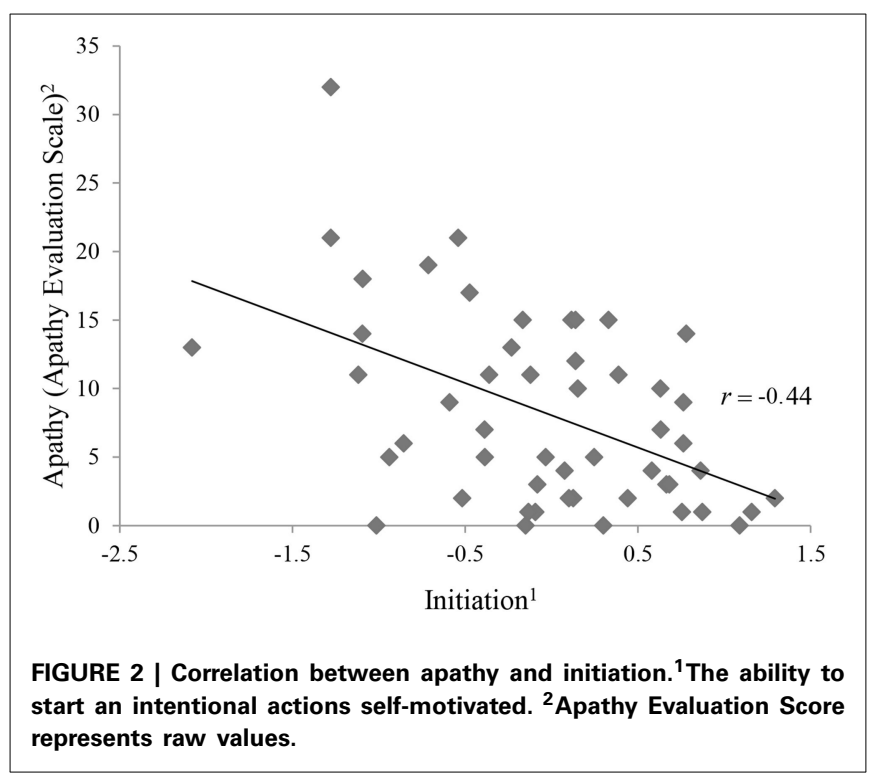

motor symptoms significantly predict apathy. In our study, not all executive processes were predictive of apathy. Neither the single executive variables categorized as shifting, nor inhibition process variables nor the $\mathrm{z}$-scored variables correlate with apathy (see Table 3).

In contrast to previous investigations (Aarsland et al., 2009; Pedersen et al., 2010; Varanese et al., 2011), the patients in this study were only slightly affected by apathy and depression. While this fact may be a limitation for the exclusion of weak but still existing relations, it helps to differentiate between distinct psychopathological syndromes; less severely affected patients are more likely to suffer from only one, instead of several disorders simultaneously.
The result regarding the relation between apathy and executive functions are in accordance with the existing literature (Pluck and Brown, 2002; Zgaljardic et al., 2007; Dujardin et al., 2009). Levy and Dubois (2006) propose dysfunctions in the prefrontal cortico-cortex-basal ganglia circuits to be involved in apathy. Dysfunctions in these circuits are also responsible for executive dysfunctions (Alvarez and Emory, 2006). Thus, it is possible that both initiation and apathy are caused by dysfunction in the prefrontal cortico-basal-ganglionic loop. However, some severely affected patients with PD do not suffer from apathy. From this, we can infer that dysfunction of the different cortico-basal loops (like the motor loop as opposed to the cingular-basal and other fronto-basal loop) is disparate.

An alternative explanation for the association between apathy and initiation might be that behavioral symptoms (i.e., lack of motivation, a loss of interest and reduced goal-directed behavior as defined by Levy and Dubois, 2006) are leading to a worse performance in initiation tasks.

Although "executive functions" are a widely accepted neuropsychological construct, the categorization of tests and variables measuring this dysfunction occur mostly in an arbitrary manner. In this study, we used the approach by Drechsler (2007) (i.e., initiation, inhibition, shifting) whereas Stuss and Alexander (2007) for example propose three different processes, i.e., energization (initiating and maintaining a response), task setting (ability of if-then setting and adjustment of contention scheduling) and monitoring (prolonged fore period effect and an increase of all subtypes of errors, including false negatives). This concept of executive processes is based on the analyses of the effects of lesions of the frontal lobes (Stuss and Alexander, 2007). Interestingly, the Drechsler's concept of initiation and Stuss' concept of energization seem to be congruent. 
Contrary to our hypothesis we did not find an association between apathy and depression. This is consistent with the assumption that apathy and depression are distinct disorders (Kirsch-Darrow et al., 2006). It is also interesting to note that severity of motor signs is not related to apathy.

In this study, we find an unexpected interaction of age and gender on apathy in PD. The literature regarding the relation of gender and apathy in PD is incongruent. Some studies reported male patients to be more severely affected by apathy (Ready et al., 2004; Pedersen et al., 2010). In contrast the female patients in a multicenter review by Martinez-Martin et al. (2012) were predominantly affected by apathy compared to male patients. Kirsch-Darrow et al. (2006) have detected a significant association between age and apathy in PD, but they did not determine an effect of gender. None of the cited studies reported an interaction of age and gender on apathy in PD. It could possibly be related to the fact that apathy was rated by a relative or a person close to the patients. Thus, this age by gender interaction has not been reported so far and needs validation.

A limitation of this study is the insufficient internal consistency for shifting and inhibition. It might be criticized, that only initiation is predictive for apathy because it has highest internal consistency. However, this possibility is unlikely as the intercorrelations of the single executive variables composing shifting and inhibition were not significantly correlated with apathy, while the single variables used for initiation were. A further limitation of this study is the relatively small sample size. In addition, only a low number of patients are strongly pronouncing apathy respectively depression. Therefore, these results have to be replicated in a larger sample of patients with PD.

In conclusion, our data support an influence of initiation, gender and age on apathy in PD.

\section{ACKNOWLEDGMENTS}

We thank the participating subjects and their caregivers. We also thank the trainees for helping with data acquisition and data entry. The financial support of Hedwig-Widmer Foundation, Gossweiler Foundation, Bangerter-Rhyner Foundation, Parkinson Schweiz are gratefully acknowledged.

\section{SUPPLEMENTARY MATERIAL}

The Supplementary Material for this article can be found online at: http://www.frontiersin.org/journal/10.3389/fnagi.2014. 00350/abstract

\section{REFERENCES}

Aarsland, D., Marsh, L., and Schrag, A. (2009). Neuropsychiatric symptoms in Parkinson's disease. Mov. Disord. 24, 2175-2186. doi: 10.1002/mds. 22589

Alvarez, J. A., and Emory, E. (2006). Executive function and the frontal lobes: a meta-analytic review. Neuropsychol. Rev. 16, 17-42. doi: 10.1007/s11065-0069002-x

Chaudhuri, K. R., Odin, P., Antonini, A., and Martinez-Martin, P. (2011). Parkinson's disease: the non-motor issues. Parkinsonism Relat. Disord. 17, 717-723. doi: 10.1016/j.parkreldis.2011.02.018

Cohen, J. (1992). A power primer. Psychol. Bull. 112, 155-159. doi: 10.1037/00332909.112.1.155

Cubo, E., Benito-Leon, J., Coronell, C., and Armesto, D. (2012). Clinical correlates of apathy in patients recently diagnosed with Parkinson's Disease: the ANIMO study. Neuroepidemiology 38, 48-55. doi: 10.1159/000334314
Delis, D., Kramer, J., Ober, B., and Kaplan, E. (1987). The California Verbal Learning Test: Administration and Interpretation. San Antonio, TX: Psychological Corporation.

Drechsler, R. (2007). Exekutive Funktionen. Z. f. Neuropsychol. 18, 233-248. doi: 10.1024/1016-264X.18.3.233

Dujardin, K., Sockeel, P., Delliaux, M., Destée, A., and Defebvre, L. (2009). Apathy may herald cognitive decline and dementia in Parkinson's disease. Mov. Disord. 24, 2391-2397. doi: 10.1002/mds.22843

Emre, M. (2003). Dementia associated with Parkinson's disease. Lancet Neurol. 2, 229-237. doi: 10.1016/S1474-4422(03)00351-X

Fahn, S. R., and Elton, R. L. (1987). Unified Parkinson's disease rating scale. Recent Dev. Park. Dis. 2, 153-163.

Folstein, M. F., Folstein, S. E., and McHugh, P. R. (1975). "Mini-mental state": a practical method for grading the cognitive state of patients for the clinician. J. Psychiatr. Res. 12, 189-198.

George, D., and Mallery, P. (2003). SPSS for Windows Step by Step: A Simple Guide and Reference, 11.0 Update, 4th Edn. Boston, MA: Allyn \& Bacon.

Gibb, W. R., and Lees, A. J. (1988). The relevance of the Lewy body to the pathogenesis of idiopathic Parkinson's disease. J. Neurol. Neurosurg. Psychiatry 51, 745-752. doi: 10.1136/jnnp.51.6.745

Grömping, U. (2006). Relative importance for linear regression in R: the package relaimpo. J. Stat. Softw. 17, 1-27. Available online at: http://www.jstatsoft. org/v17/i01

Hautzinger, M., Bailer, M., Worall, H., and Keller, F. (1995). BDI Beck-DepressionsInventar Testhandbuch (2. Auflage). Bern: Verlag Hans Huber.

Kirsch-Darrow, L., Fernandez, H. F., Marsiske, M., Okun, M. S., and Bowers, D. (2006). Dissociating apathy and depression in Parkinson disease. Neurology 67, 33-38. doi: 10.1212/01.wnl.0000230572.07791.22

Leentjens, A. F. G., Dujardin, K., Marsh, L., Martinez-Martin, P., Richard, I. H., Starkstein, S. E., et al. (2008). Apathy and anhedonia rating scales in Parkinson's disease: critique and recommendations. Mov. Disord. 23, 2004-2014. doi: $10.1002 / \mathrm{mds} .22229$

Levy, M. L., Cummings, J. L., Fairbanks, L. A., Masterman, D., Miller, B. L., Craig, A. H., et al. (1998). Apathy is not depression. J. Neuropsychiatry Clin. Neurosci. 10, 314-319. doi: 10.1176/jnp.10.3.314

Levy, R., and Dubois, B. (2006). Apathy and the functional anatomy of the prefrontal cortex-basal ganglia circuits. Cereb. Cortex 16, 916-928. doi: 10.1093/cercor/bhj043

Lueken, U., Seidl, U., Schwarz, M., Völker, L., Naumann, D., Mattes, K., et al. (2006). Psychometric properties of a german version of the apathy evaluation scale. Fortschr. Neurol. Psychiatr. 74, 714-722. doi: 10.1055/s-2006-9 32164

Martinez-Martin, P., Pecurariu, C. F., Odin, P., Hilten, J. J., van Antonini, A., Rojo-Abuin, J. M., et al. (2012). Gender-related differences in the burden of non-motor symptoms in Parkinson's disease. J. Neurol. 259, 1639-1647. doi: 10.1007/s00415-011-6392-3

Miyake, A., Friedman, N. P., Emerson, M. J., Witzki, A. H., Howerter, A., and Wager, T. D. (2000). The unity and diversity of executive functions and their contributions to complex "Frontal Lobe" tasks: a latent variable analysis. Cogn. Psychol. 41, 49-100. doi: 10.1006/cogp.1999.0734

Morris, J. C., Heyman, A., Mohs, R. C., Hughes, J. P., van Bell, G., and Fillenbaum, G. (1989). The consortium to establish a registry for Alzheimer's disease (CERAD). Part I. Clinical and neuropsychological assessment of Alzheimer's disease. Neurol. 39, 43-63.

Nelson, H. E. (1976). A modified card sorting test sensitive to frontal lobe defects. Cortex 12, 313-324. doi: 10.1016/S0010-9452(76)80035-4

Pedersen, K. F., Alves, G., Brønnick, K., Aarsland, D., Tysnes, O.-B., and Larsen, J. P. (2010). Apathy in drug-naïve patients with incident Parkinson's disease: the Norwegian ParkWest study. J. Neurol. 257, 217-223. doi: 10.1007/s00415009-5297-x

Pluck, G. C., and Brown, R. G. (2002). Apathy in Parkinson's disease. J. Neurol. Neurosurg. Psychiatry 73, 636-642. doi: 10.1136/jnnp.73.6.636

R Core Team. (2012). R: A Language And Environment for Statistical Computing [Online]. Vienna: R Foundation for Statistical Computing. Available online at: http://www.r-project.org/

Ready, R. E., Friedman, J., Grace, J., and Fernandez, H. (2004). Testosterone deficiency and apathy in Parkinson's disease: a pilot study. J. Neurol. Neurosurg. Psychiatry 75, 1323-1326. doi: 10.1136/jnnp.2003.032284 
Regard, M., Strauss, E., and Knapp, P. (1982). Children's production on verbal and non-verbal fluency tasks. Percept. Mot. Skills 55, 839-844. doi: 10.2466/pms.1982.55.3.839

Reijnders, J. S. A. M., Scholtissen, B., Weber, W. E. J., Aalten, P., Verhey, F. R. J., and Leentjens, A. F. G. (2010). Neuroanatomical correlates of apathy in Parkinson's disease: a magnetic resonance imaging study using voxel-based morphometry. Mov. Disord. 25, 2318-2325. doi: 10.1002/mds.23268

Reitan, R. M. (1958). Validity of the Trail Making Test as an indicator of organic brain damage. Percept. Mot. Skills 8, 271-276. doi: 10.2466/pms.1958.8.3.271

Schrag, A., Barone, P., Brown, R. G., Leentjens, A. F. G., McDonald, W. M., Starkstein, S., et al. (2007). Depression rating scales in Parkinson's disease: critique and recommendations. Mov. Disord. 22, 1077-1092. doi: $10.1002 / \mathrm{mds} .21333$

Starkstein, S. E., Brockman, S., and Hayhow, B. D. (2012). Psychiatric syndromes in Parkinson's disease. Curr. Opin. Psychiatry 25, 468-472. doi: 10.1097/YCO.0b013e3283577ed1

Starkstein, S. E., Merello, M., Jorge, R., Brockman, S., Bruce, D., and Power, B. (2009). The syndromal validity and nosological position of apathy in Parkinson's disease. Mov. Disord. 24, 1211-1216. doi: 10.1002/mds.22577

Stroop, J. R. (1935). Studies of interference in serial verbal reactions. J. Exp. Psychol. 18, 643-662. doi: 10.1037/h0054651

Stuss, D. T., and Alexander, M. P. (2007). Is there a dysexecutive syndrome? Philos. Trans. R. Soc. B Biol. Sci. 362, 901-915. doi: 10.1098/rstb.2007.2096

Thurstone, L. L., and Thurstone, T. M. (1948). The Chicago Test of Primary Abilities. Chicago: Science Research Associates.

Varanese, S., Perfetti, B., Ghilardi, M. F., and Di Rocco, A. (2011). Apathy, but not depression, reflects inefficient cognitive strategies in Parkinson's disease. PLOS ONE 6:e17846. doi: 10.1371/journal.pone.0017846

Venables, W. N., and Ripley, B. D. (2002). Modern Applied Statistics with S. New York, NY: Springer.

Zesiewicz, T. A., Sullivan, K. L., Arnulf, I., Chaudhuri, K. R., Morgan, J. C., Gronseth, G. S., et al. (2010). Practice parameter: treatment of nonmotor symptoms of Parkinson disease report of the quality standards subcommittee of the american academy of neurology. Neurology 74, 924-931. doi: 10.1212/WNL.0b013e3181d55f24

Zgaljardic, D. J., Borod, J. C., Foldi, N. S., Rocco, M., Mattis, P. J., Gordon, M. F., et al. (2007). Relationship between self-reported apathy and executive dysfunction in nondemented patients with Parkinson disease. Cogn. Behav. Neurol. 20, 184-192. doi: 10.1097/WNN.0b013e318145a6f6

Zimmermann, P., and Fimm, B. (2007). Testbatterie zur Aufmerksamkeitsprüfung. Herzogenrath: Psytest Psychologische Testsysteme.

Zimmermann, R., Gschwandtner, U., Benz, N., Hatz, F., Schindler, C., Taub, E., et al. (2014). Cognitive training in Parkinson disease Cognitionspecific vs. nonspecific computer training. Neurology 82, 1219-1226. doi: 10.1212/WNL.0000000000000287

Conflict of Interest Statement: The authors declare that the research was conducted in the absence of any commercial or financial relationships that could be construed as a potential conflict of interest.

Received: 06 August 2014; accepted: 28 December 2014; published online: 15 January 2015.

Citation: Meyer A, Zimmermann R, Gschwandtner U, Hatz F, Bousleiman H, Schwarz N and Fuhr P (2015) Apathy in Parkinson's disease is related to executive function, gender and age but not to depression. Front. Aging Neurosci. 6:350. doi: 10.3389/fnagi.2014.00350

This article was submitted to the journal Frontiers in Aging Neuroscience.

Copyright (c) 2015 Meyer, Zimmermann, Gschwandtner, Hatz, Bousleiman, Schwarz and Fuhr. This is an open-access article distributed under the terms of the Creative Commons Attribution License (CC BY). The use, distribution or reproduction in other forums is permitted, provided the original author(s) or licensor are credited and that the original publication in this journal is cited, in accordance with accepted academic practice. No use, distribution or reproduction is permitted which does not comply with these terms. 